Iranian Journal of Pathology | ISSN: 2345-3656

\title{
Evaluation of Serum Pentraxin-3 Level in Patients with Acute Myocardial Infarction Compared with Control Group
}

\author{
Alireza Firouzjahi ${ }^{1,2}$, Saeedeh Eris ${ }^{3}$, Seyed Farzad Jalali ${ }^{1}$, Ali Bijani ${ }^{4}$, Mohammad Ranaee ${ }^{5 *}$ \\ 1. The Clinical Research Development Unit of Rouhani Hospital, Babol University of Medical Sciences, Babol, Iran \\ 2. Cellular and Molecular Biology Research Center, Health Research Institute, Babol University of Medical Sciences, Babol, \\ Iran \\ 3. Student Committee Research, Babol University of Medical Sciences, Babol, Iran \\ 4. Social Determinants of Health Research Center, Health Research Institute, Babol University of Medical Sciences, Babol, Iran \\ 5. Cancer Research Center, Health Research Institute, Babol University of Medical Sciences, Babol, Iran
}

\begin{tabular}{c}
\hline KEYWORDS \\
\hline Pentraxin 3, Troponin I, \\
Myocardial ischemia, \\
Coronary angiography \\
Scan to discover online \\
Q \\
Main Subjects: \\
Cardiovascular Pathology \\
Received 02 May 2020; \\
Accepted 18 Jan 2021; \\
Published Online 09 May 2021; \\
\hline
\end{tabular}

$\underline{\text { 10.30699/IJP.20201.116962.2268 }}$

\section{ABSTRACT}

Background \& Objective: The aim of this study was to measure serum pentraxin 3 (PTX3) in patients with acute myocardial infarction (MI) and compare it with the control group.

Methods: In this case-control study, 60 patients with MI ( \pm ST-segment elevation) were included in the case group , and those with symptoms suspicious for coronary artery disease (CAD) and with no abnormal findings in angiography and troponin I level less than 99th percentile of normal population were included as a control group $(N=30)$. Serum PTX3 and troponin I were measured.

Results: In this study, 60 patients including 34 men and 26 women were included in the case group (mean age: $61.4 \pm 8.86$ years in non-ST-segment elevation myocardial infarction [NSTEMI] subgroup and mean age: $57.9 \pm 9.49$ years in ST-segment elevation myocardial infarction [STEMI] subgroup), as well as 13 men and 17 women as the control group (mean age: $55.47 \pm 10.09$ years). PTX3 level was higher in MI cases $(1128.4 \pm 1205 \mathrm{pg} / \mathrm{mL})$ compared to controls $(394.5 \pm 170.40 \mathrm{pg} / \mathrm{mL})(P=0.001)$. There was no relationship between ejection fraction (EF) and PTX3 level in the MI group. The area under the ROC curve (AUC) of PTX3 in MI was presented by 0.828 (AUC=0.828) $(P>0.001)$. We defined three different cutoffs for PTX in this study, in which the cutoff $\geq 400 \mathrm{pg} / \mathrm{mL}$ had the highest sensitivity (92\%), and the cutoff $\geq 700$ $\mathrm{pg} / \mathrm{mL}$ had the highest specificity (97\%).

Conclusion: According to the results of this study, PTX3 as an inflammatory marker showed higher level in patients with MI, especially in STEMI cases. Therefore, combined evaluation of troponin I and PTX3 levels would be associated with more accuracy in diagnosis of MI.

Copyright $\odot$ 2021. This is an open-access article distributed under the terms of the Creative Commons Attribution- 4.0 International License which permits Share, copy and redistribution of the material in any medium or format or adapt, remix, transform, and build upon the material for any purpose, even commercially.

\section{Introduction}

Cardiovascular diseases (CVDs) are among the most common causes of mortality and morbidity all over the world. Previous studies have suggested that different factors (such as age, gender, diabetes mellitus, hyperlipidemia, and hypertension) are responsible for CVD etiology (1); however, some pieces of evidence showed that inflammation makes atherosclerotic lesions prone to the erosion and rupture (1).

Acute coronary syndrome (ACS) includes unstable angina, myocardial infarction (MI) without STsegment elevation (non-Q wave MI or non-STsegment elevation myocardial infarction [NSTEMI]), and MI with ST-segment elevation (Q wave elevation or ST-segment elevation myocardial infarction [STEMI]) (2).

Clinical differentiation between cardiac and noncardiac pains needs a combination of the patient's history, electrocardiogram (ECG), and biomarkers (2).

In the pentraxin (PTX) family, in addition to Creactive protein (CRP), PTX3 (defined as a long PTX) is locally secreted by smooth muscle and endothelial cells or by monocytes/macrophages exposed to the first inflammatory signals (such as interleukin 1, tumor necrosis factor- $\alpha$, oxidized low-density lipoprotein, 
and bacterial products) (3). PTX3 also increases in ACS and congestive heart failure (CHF), which shows its effective role in local vascular inflammation and cardiovascular system damage (4-6).

The peak level of PTX3 will be reached seven hours after presenting symptoms in STEMI and will have an independent predictive role in three-month mortality when measured during the first day (4).

This study was designed to measure PTX3 in patients with $\mathrm{MI}$ and compare it with the control group.

\section{Material and Methods}

This study was approved by the Local Ethics Committee of Babol University of Medical Sciences, and informed consent has been obtained from all individuals included in this study.

In this case-control study, a total of 60 patients (34 men and 26 women) with coronary artery disease (CAD) were enrolled, who were referred to Ayatollah Rohani Hospital; Babol, Iran, also, 30 control subjects were included in the control group. All of these individuals $(N=90)$ were categorized into three groups as follows:

1. MI with STEMI in ECG and rise in cardiac enzymes

2. MI without NSTEMI in ECG and rise in cardiac enzymes

3. Control group: Sex and age-matched (40-70 years) patients were selected based on symptoms suspicious for CAD and no abnormal findings in angiography and troponin I level less than 99th percentile of normal population.

Subjects with CHF, renal and liver failures, and acute inflammatory diseases, as well as patients receiving steroids, immunosuppressant drugs, and nonsteroidal anti-inflammatory drugs (NSAIDs), except for low-dose aspirin, were excluded from the study.

During the first 24 hours (preferably during the first 12 hours) of patients' admission, 5 cc venous blood was taken, and PTX3 and troponin I were measured using the Human Pentraxin 3 Kit (Biovendor Company, Brno, Czechia) by the enzyme-linked immunosorbent assay (ELISA) method. Angiography was done based on clinical status and along with diagnosis and treatment process during the first to third day of admission, except in those with critical status that was done urgently.

Demographic data, such as age, gender, weight and height, hypertension, hypercholesterolemia, family history of CVD, body mass index (BMI), and smoking, were recorded in a checklist (7). MI was classified as follows (8):

1. Anterior: septal (v1-v2) - mid anterior (v3-v4) lateral (v5-v6)

2. Extensive anterior (v1-v6)

3. Inferior (II, III, and aVF)

4. Right ventricle (Rv3-Rv4)
5. Posterior (tall R wave and ST depression in v1v2)

Data were analyzed using Chi-square, $t$, ANOVA, and Mann-Whitney tests.

\section{Results}

In this study, 30 patients with STEMI, 30 with NSTEMI, and 30 controls were compared. There was no significant difference between all groups regarding age, sex, cigar, and other demographic variables, except in the history of hyperlipidemia (see Table 1).

No history of ischemic heart disease (IHD) was reported in the control group, but there were 21 cases (35\%) with IHD in the MI group ( $P>0.001)$.

PTX3 level was significantly higher in the cases with MI $(1128.4 \pm 1205 \mathrm{pg} / \mathrm{mL})$ compared to the control group (394.5 $\pm 170.40 \mathrm{pg} / \mathrm{mL} ; P>0.001)$.

Kruskal-Wallis and Mann-Whitney tests showed a significant difference between PTX3 level in the normal group to each of the STEMIs $(P>0.001)$ and NSTEMIs $(P=0.053)$. As shown in Figure 1 , PTX3 level was significantly higher in the STEMI group $(1367 \pm 1358 \mathrm{pg} / \mathrm{mL})$ than in the NSTEMI $(890 \pm 996$ $\mathrm{pg} / \mathrm{mL}$ ) group.

Troponin level was also significantly higher in the STEMI group $(11.96 \pm 6.4 \mathrm{ng} / \mathrm{mL})$ than in the NSTEMI $(5.62 \pm 6.3 \mathrm{ng} / \mathrm{mL})$ group.

Spearman correlation coefficient was 0.338 for troponin and PTX3 $(P=0.134)$ and 0.201 for age and PTX3 $(P=0.375)$.

No one in the MI group had ejection fraction (EF) upper than 55\%. In the STEMI group, 20 cases (66.7\%) and in the NSTEMI group, 14 cases (46.7\%) had $\mathrm{EF}=30 \%-45 \%$. There was no significant difference between these two groups.

There was no relationship between EF and PTX3 in the MI group. However, there were higher PTX and troponin levels in lower EF (not significant). Forty-one cases had $\mathrm{EF}<45 \%$ with PTX $1298 \pm 1335$, and 19 cases had $\mathrm{EF} \geq 45 \%$ with PTX $761 \pm 766(P=0.076)$.

Anterior MI was seen in 19 (63.3\%) NSTEMI and 17 (56.2\%) STEMI cases. Inferior MI was reported in seven NSTEMI and 11 STEMI patients.

Left anterior descending coronary artery (LAD) was the most-seen involved vessel in 38 (63.3\%) cases of both MI groups, and then right coronary artery (RCA) had the second position in 16 (26.6\%) cases.

Involved vessels in angiography showed a significant relationship with the serum PTX3 level; it was higher in LAD, then RCA, and left circumflex coronary artery (LCX) $(P>0.001)$. Five cases had extensive anterior MI with PTX3 level 2465 \pm 2170 , and 55 cases had other MI with PTX 1007 \pm 1028 $(P=0.042)$.

There was a significant relationship between the numbers of involved vessels and PTX ( $r=0.516$, $P>0.001)$. 
As shown in Figure 2, sensitivity and specificity of PTX in MI was presented by the area under the ROC curve (AUC) of 0.828 , showing a high overall discriminatory ability of PTX in MI (AUC=0.828; 95\% CI, 0.739-0.918; $P>0.001)$.

In patients suspicious for CAD without any abnormal findings in angiography and troponin I level less than 99th percentile of normal population, there was no significant relationship between the PTX serum level and demographic variables.

Three different cutoffs were offered for PTX and for each cutoff, sensitivity, specificity, positive predictive value \& negative predictive value have been calculated. As shown in Table 2, the cutoff $\geq 400$ had the highest sensitivity, and the cutoff $>700$ had the highest specificity; however, the best sensitivity and specificity concurrently is $\geq 500 \mathrm{pg} / \mathrm{mL}$.

Table 1. Comparing demographic variables between controls and MI cases

\begin{tabular}{|c|c|c|c|c|}
\hline \multirow{2}{*}{\multicolumn{2}{|c|}{ Variables }} & \multicolumn{2}{|c|}{ Group } & \multirow{2}{*}{ P-value } \\
\hline & & Control & MI & \\
\hline \multirow{2}{*}{ Gender } & male & $13(43.3)$ & $34(56.7)$ & \multirow{2}{*}{0.23} \\
\hline & Female & $17(56.7)$ & $26(43.3)$ & \\
\hline \multirow{2}{*}{ Smoking } & No & $25(83.3)$ & $41(68.3)$ & \multirow{2}{*}{0.13} \\
\hline & Yes & $5(16.7)$ & $19(31.7)$ & \\
\hline \multirow{2}{*}{ History of hyperlipidemia } & No & $28(93.3)$ & $40(66.7)$ & \multirow{2}{*}{0.006} \\
\hline & Yes & $2(9.1)$ & $20(33.3)$ & \\
\hline \multirow{2}{*}{ History of diabetes mellitus } & No & $21(70)$ & $40(66.7)$ & \multirow{2}{*}{0.75} \\
\hline & Yes & $9(30)$ & $20(33.3)$ & \\
\hline \multirow{2}{*}{ History of hypertension } & No & $14(46.7)$ & 38 (63.3) & \multirow{2}{*}{0.13} \\
\hline & Yes & $16(53.3)$ & $22(36.7)$ & \\
\hline \multirow{2}{*}{ Family history of heart diseases } & No & $24(80)$ & $46(76.7)$ & \multirow{2}{*}{0.72} \\
\hline & Yes & $6(20)$ & $14(23.3)$ & \\
\hline \multicolumn{2}{|c|}{ Age (Mean; SD); years } & $55.47(10.1)$ & $59.65(9.3)$ & 0.053 \\
\hline
\end{tabular}

Table 2. Sensitivity, specificity, positive predictive value, and negative predictive values of 3 different cutoffs for PTX in MI patients

\begin{tabular}{|c|c|c|c|c|c|c|}
\hline $\begin{array}{c}\text { Serum } \\
\text { PTX level }\end{array}$ & $\begin{array}{l}\text { Sensitivity } \\
(\mathrm{CI} * 95 \%)\end{array}$ & $\begin{array}{c}\text { Specificity } \\
\text { (CI95\%) }\end{array}$ & $\begin{array}{c}\text { Negative likelihood } \\
\text { ratio } \\
(\mathrm{CI} 95 \%)\end{array}$ & $\begin{array}{c}\text { Positive } \\
\text { likelihood ratio } \\
\text { (CI95\%) }\end{array}$ & $\begin{array}{c}\text { NPV } \\
\text { (CI95\%) }\end{array}$ & $\begin{array}{c}\text { PPV } \\
\text { (CI95\%) }\end{array}$ \\
\hline $\begin{array}{c}\leq 400 \\
\mathrm{pg} / \mathrm{mL}\end{array}$ & $\begin{array}{c}92 \% \\
(85-99)\end{array}$ & $\begin{array}{c}50 \% \\
(32-68)\end{array}$ & $\begin{array}{c}0.17 \\
(0.07-0.42)\end{array}$ & $\begin{array}{c}1.83 \\
(1.27-2.64)\end{array}$ & $\begin{array}{c}75 \% \\
(56-94)\end{array}$ & $\begin{array}{c}79 \% \\
(69-88)\end{array}$ \\
\hline $\begin{array}{c}\geq 500 \\
\mathrm{pg} / \mathrm{mL}\end{array}$ & $\begin{array}{c}77 \% \\
(66-88)\end{array}$ & $\begin{array}{c}77 \% \\
(62-92)\end{array}$ & $\begin{array}{c}0.3 \\
(0.18-0.49)\end{array}$ & $\begin{array}{c}3.30 \\
(1.70-6.41)\end{array}$ & $\begin{array}{c}62 \% \\
(47-78)\end{array}$ & $\begin{array}{c}87 \% \\
(78-96)\end{array}$ \\
\hline $\begin{array}{c}\leq 700 \\
\mathrm{pg} / \mathrm{mL}\end{array}$ & $\begin{array}{c}38 \% \\
(25-51)\end{array}$ & $\begin{array}{c}97 \% \\
(90-100)\end{array}$ & $\begin{array}{c}0.64 \\
(0.52-0.79)\end{array}$ & $\begin{array}{c}11.5 \\
(1.63-81.12)\end{array}$ & $\begin{array}{c}44 \% \\
(32-56)\end{array}$ & $\begin{array}{c}96 \% \\
(88-100)\end{array}$ \\
\hline
\end{tabular}

*Confidence interval

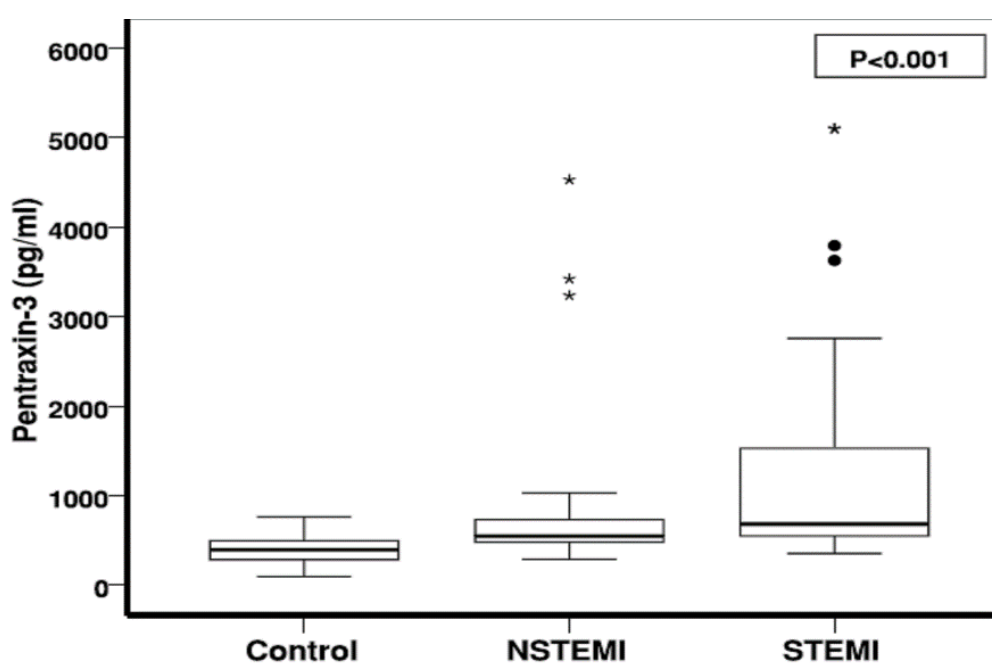

Fig. 1. Comparing the mean PTX-3 level between MI and normal group 


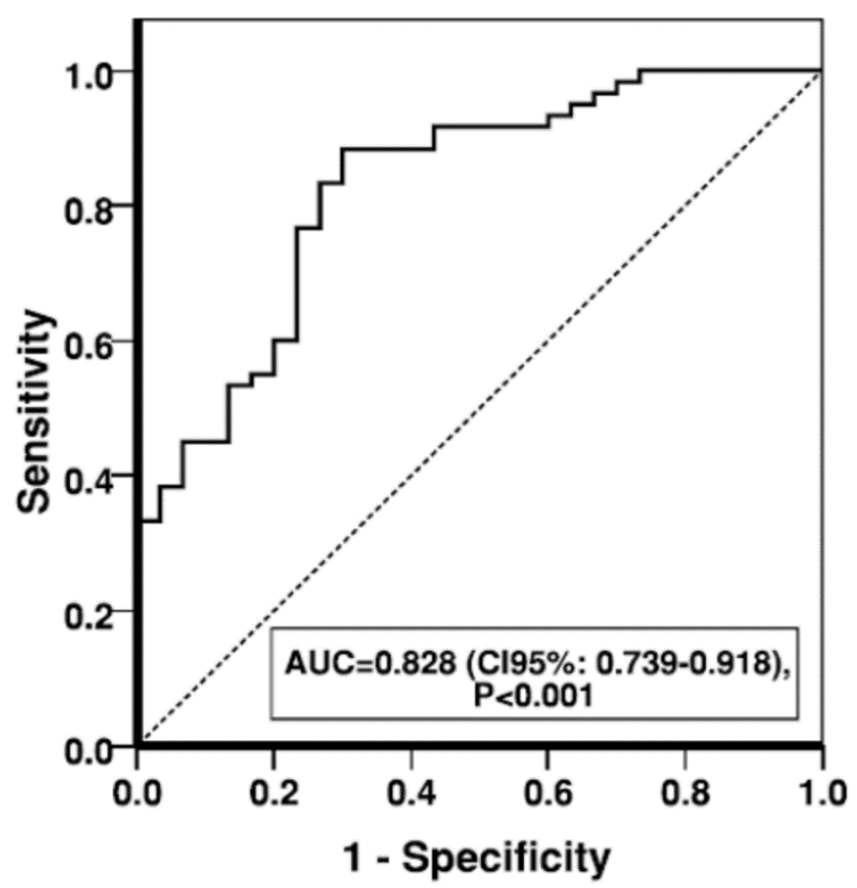

Fig. 2. Area under curve of PTX-3 serum level in MI patients

\section{Discussion}

In this study, in MI and normal patients (who underwent angiography), there was no significant relationship between PTX and demographic variables. However, some studies have reported it as significant $(3,9)$.

Present results showed that in MI cases (STEMI and NSTEMI), PTX was significantly higher than the control group. The mean PTX level was also higher in the STEMI group compared to the NSTEMI group. This was also seen in previous studies. Rashtizadeh et al. in Iran (9), Ma et al. in China (10), and Eggers et al. in Canada (3) reported a significantly higher level of PTX in MI cases, although the studied populations and sample sizes were different compared to this study; however, a higher level of PTX as an inflammatory marker in ACS was commonly seen.

In the present study, the numbers and locations of involved vessels and sites of MI had a significant relationship with PTX. PTX3 was significantly higher in LAD stenosis, extensive anterior MI, and higher numbers of involved vessels. This was not reported in other studies.

Rashtchizadeh et al. (9) reported a relationship between PTX level and age and hypertension that was not seen in the present study. In Eggers et al.'s study, PTX was independently related to female gender and cardiac troponin level in NSTE-ACS, but not to age or other cardiovascular factors (3).

In this study, troponin level was significantly higher in STEMI than in NSTEMI. In the MI group, there was no significant relationship between EF and PTX or troponin, but PTX3 was higher in lower EF, although it was clinically important and shows a higher inflammation level in MI cases. The sensitivity and specificity of PTX was high in MI patients.

Rashtchizadeh et al.'s study reported an AUC of 0.078 for PTX which had better diagnostic ability compared to high-sensitivity-CRP (hs-CRP) (9). In Rashtchizdeh et al.'s study, the studied population was diabetic patients that have strong risk factors for CVDs. They also compared the sensitivity and specificity of PTX and hs-CRP (9), which was not performed in this study.

Kume et al. reported AUC $=0.901$ for PTX in ACS and concluded that the combination of troponin and PTX would diagnose the MI with higher accuracy (11).

In this study, among three cutoffs defined for PTX, it was seen that the cutoff level $\geq 400 \mathrm{pg} / \mathrm{mL}$ had the highest sensitivity, and the cutoff $>700 \mathrm{pg} / \mathrm{mL}$ had the highest specificity. These cutoffs were defined in the present study because this kit is not used as a routine test in our country, and it is used for research. Thus, it should be evaluated more carefully in further studies.

The limitation of this study is that we could not evaluate in-hospital mortality (short-term follow-up) rate, which was considered as one of our goals. Thus, we were looking for a prognostic factor. However, due to the small statistical population (two cases of mortality), no statistical analysis was possible. We suggest that another study be done with more samples.

\section{Conclusion}

According to the results of this study, PTX3 was higher in patients with MI, especially in STEMI cases. Therefore, the combination of troponin I and PTX3 levels would diagnose MI with higher accuracy. 


\section{Acknowledgements}

Authors would like to express their gratitude to the Clinical Research and Development Unit of Ayatollah Rouhani Hospital in Babol, Iran.

\section{Conflict of Interest}

The authors declare no conflict of interest.

\section{References}

1. Beatty AL, Ku IA, Bibbins-Domingo K, Christenson RH, DeFilippi CR, Ganz P, et al. Traditional risk factors versus biomarkers for prediction of secondary events in patients with stable coronary heart disease: from the heart and soul study. Journal of the American Heart Association. 2015;4(7):e001646. [DOI:10.1161/JAHA.114.001646] [PMID] [PMCID]

2. Sarkees ML, Bavry AA. Acute coronary syndrome (unstable angina and non-ST elevation MI). BMJ clinical evidence. 2009;2009.

3. Eggers KM, Armstrong PW, Califf RM, Johnston N, Simoons ML, Venge P, et al. Clinical and prognostic implications of circulating pentraxin 3 levels in non STelevation acute coronary syndrome. Clinical biochemistry. 2013;46(16):1655-9. [DOI:10.1016/j.clinbiochem.2013.08.014] [PMID]

4. Matsui S, Ishii J, Kitagawa F, Kuno A, Hattori K, Ishikawa $\mathrm{M}$, et al. Pentraxin 3 in unstable angina and non-ST-segment elevation myocardial infarction. Atherosclerosis. 2010;210(1):220-5 [DOI:10.1016/j.atherosclerosis.2009.10.033] [PMID]

5. Nebuloni M, Pasqualini F, Zerbi P, Lauri E, Mantovani A, Vago L, et al. PTX3 expression in the heart tissues of patients with myocardial infarction and infectious myocarditis. Cardiovascular Pathology. 2011;20(1):e27-e35. [DOI:10.1016/j.carpath.2010.02.005] [PMID]

6. Inoue K, Sugiyama A, Reid PC, Ito Y, Miyauchi K, Mukai S, et al. Establishment of a high sensitivity plasma assay for human pentraxin3 as a marker for unstable angina pectoris. Arteriosclerosis, thrombosis, and vascular biology. 2007;27(1):161-7. [DOI:10.1161/01.ATV.0000252126.48375.d5] [PMID]

7. Garvey W, Mechanick J, Brett E, Garber A, Hurley D, Jastreboff A, et al. Reviewers of the AACE/ACE Obesity Clinical Practice Guidelines. American Association of Clinical Endocrinologists and American College of Endocrinology comprehensive clinical practice guidelines for medical care of patients with obesity. Endocr Pract. 2016;22(Suppl 3):1-203. [DOI:10.4158/EP161365.GL] [PMID]

8. Bonow RO, Mann DL, Zipes DP, Libby P. Braunwald's Heart Disease E-Book: A Textbook of Cardiovascular Medicine: Elsevier Health Sciences; 2011.

9. Rashtchizadeh N, Sede SA, Ghaffari MA, Mohammadzadeh G, Majidi S. Associations of pentraxin 3 with presence and severity of coronary artery disease in type 2 diabetes patients/[Tip 2 diyabet hastalarında koroner arter hastalığı varlığının ve şiddetinin pentraxin 3 ile ilişkisi]. Turkish Journal of Biochemistry. 2015;40(1):37-43 [DOI:10.5505/tjb.2015.60024]

10. Ma B, Simala-Grant JL, Taylor DE. Fucosylation in prokaryotes and eukaryotes. Glycobiology. 2006;16(12):158R-84R. [DOI:10.1093/glycob/cwl040] [PMID]

11. Kume N, Mitsuoka H, Hayashida K, Tanaka M. Pentraxin 3 as a biomarker for acute coronary syndrome: comparison with biomarkers for cardiac damage. Journal of cardiology. 2011;58(1):38-45. [DOI:10.1016/j.jjcc.2011.03.006] [PMID] 